\title{
Customer orientation, conflict, and innovativeness in Japanese sales departments
}

\author{
Makoto Matsuo
}

Otaru University of Commerce, 3-5-21 Midori, Otaru City, Hokkaido, Japan 047-8501

Received 1 March 2005; revised 1 May 2005; accepted 1 June 2005.

Journal of Business Research, 59 (2006) 242-250.

\section{Abstract}

There has been an argument over whether customer orientation enhances innovation; moreover, the customer orientation/innovation mechanism remains unclear. This study investigated how customer orientation influences innovativeness through three types of conflict using a sample of 193 sales departments in Japanese firms. A structural equation modeling revealed that (1) customer orientation was positively related to task conflict and negatively related to process conflict, and that (2) task conflict was positively related to innovativeness, while process and relationship conflict was negatively related to innovativeness. The results suggest that customer orientation influences innovativeness by enhancing positive conflict and reducing negative conflict.

Keywords: Customer orientation; Conflict; Innovativeness; Sales department; Japan 


\section{Introduction}

Marketing research has shown that firms are more successful when they focus on their customers' needs (Donavan et al., 2004 and Kennedy et al., 2003). Although some empirical studies have investigated the relationship between customer orientation and innovation (e.g., Gatignon and Xuereb, 1997, Han et al., 1998 and Lukas and Ferrell, 2000), they have failed to show the mechanism by which customer orientation promotes innovation. This study explored how customer orientation affects innovativeness, or a perceived work environment that encourages innovative behavior, by examining conflicts in the sales departments of Japanese firms.

One example indicating the importance of customer orientation in generating creative conflict within an organization is the case of Nissan. Nissan's CEO Carlos Ghosn commented: "The firm can continue to exist by getting rid of barriers between departments and acting from customer's point of view (Ghosn, 2001a)." When different opinions clash among members at an executive meeting in Nissan, Ghosn always tries to encourage members to make decision in terms of customer satisfaction and profit (Ghosn, 2001b). This indicates that customer orientation plays an important role in integrating organizational members who have diverse perspectives in different sections.

There are two reasons why this study is focused on the conflict in explaining the relationship between customer orientation and innovativeness. First, positive conflict or tension within an organization is essential for encouraging members to come up with innovative ideas, while negative conflicts often hinder their creativity (Brown and Duguid, 1991, Dougherty, 1992, Leonard-Barton, 1995 and Leonard-Barton and Straus, 1997). Second, customer orientation, as a shared belief or value, can restrain negative conflicts within an organization and integrate members' diverse perspectives and ideas (Dougherty, 1992 and Eisenhardt and Santos, 2002). Despite the importance of the relationship between customer orientation, conflict, and innovation, it has not been examined in past research.

Sales departments were chosen because salespeople, as boundary spanners, play critical roles in the service-delivery process; a capable sales department, therefore, can be one source of competitive advantage (Dubinsky et al., 1996, Singh, 1998, Shepherd, 1999 and Weitz and Bradford, 1999). According to Anderson and Narus (1995), excellent manufacturing companies tend to profit from providing additional service, rather than 
through the product itself. By studying the customer orientation/innovativeness relationship through conflicts in sales departments, it may be possible to find a mechanism for customer-oriented service innovation.

\section{Conceptual framework}

\subsection{Customer orientation/innovation linkage}

There has been no consensus about the effect of customer orientation on innovation. Some researchers insist that customer orientation sometimes inhibits innovative product development and $R \& D$ research activities. Critics have suggested that listening too closely to current markets can constitute a barrier to commercializing technology (Leonard-Barton, 1995). Christensen and Bower (1996) have reported that some firms lose their leadership positions in industry during periods of industry discontinuity because they listen too carefully to their customers. This implies that listening to customers' voices too closely leads firms to maintain the status quo, and thus cannot imagine the benefits of emergent technologies and new materials (Ulwick, 2002). They suggest that firms need to go beyond being 'customer-led' (Hamel and Prahalad, 1994).

Despite the argument, only a few studies have examined empirically the relationship between customer orientation and innovation (Lukas and Ferrell, 2000). In a survey of US firms, Gatignon and Xuereb (1997) found that customer orientation promotes product innovation when demand is uncertain. Han et al. (1998) examined US banks and reported a positive relationship between customer orientation and technical and administrative innovation. Using a sample of US manufacturing firms Lukas and Ferrell (2000) demonstrated that customer orientation increases the introduction of new-to-the-world products and reduces the launching of me-too-products. These findings indicate that innovation mediates the relationship between customer orientation and performance, while the actual mechanism by which customer orientation enhances innovation remains unclear.

This study contributes to the literature in two respects. First, we explored the process by which customer orientation influences innovation in terms of conflict. The customer orientation/conflict relationship was pointed out in prior research (e.g., Dougherty, 1992 and Eisenhardt and Santos, 2002), but never examined empirically. Second, this study classified the conflict into three types and found the characteristics of conflict influence 
innovativeness within an organization. Although past research in intra-group conflict reported the conflict/performance relationship, few studies have investigated the relationship between conflict and innovativeness.

\subsection{Customer orientation}

Narver and Slater (1990) defined customer orientation as "the sufficient understanding of one's target buyers to be able to create superior value for them continuously" (p.21). Similarly, customer orientation is defined as "the set of beliefs that puts the customer's interest first" (Desphande et al., 1993, p.27), or "firm's ability and will to identify, analyze, understand, and answer user needs" (Gatignon and Xuereb, 1997, p.78).

Narver and Slater (1990) conceptualized customer orientation as the part of market orientation that consists of three behavioral components: customer orientation, competitor orientation, and interfunctional coordination. Market orientation, which has a broader meaning than that of customer orientation, refers to "the organization culture that most effectively and efficiently creates the necessary behaviors for the creation of superior value for buyers" (Narver and Slater, 1990, p.21). Of the three components of market orientation, this study focuses on customer orientation, because customer orientation is the most fundamental aspect of market oriented corporate culture (e.g., Desphande et al., 1993 and Lawton and Parasuraman, 1980), and it is based on a marketing concept that promote putting the interests of customers first (Han et al., 1998). Desphande et al. (1993) regard customer orientation and market orientation as synonymous.

\subsection{Innovativeness}

Organizational innovation is generally viewed as the adoption of an internally generated or purchased device, system, policy, program, process, product, or service that is new to the adopting organization (Damanpour, 1991 and Damanpour and Gopalakrishnan, 2001). According to this definition, products and services are not necessarily new to the market or industry. Even when a firm imitates another firm's product or system, it can be recognized as an organizational innovation if it is new to the adopting firm. Conversely, organizational innovativeness can be distinguished from organizational innovation. Hurley and Hult (1998) view innovativeness as the organization's orientation toward innovation (p.44). In previous research, innovativeness has been one of the central dimensions used to describe organizational climate or culture (e.g., 
Chatman and Jhen, 1994, Hult et al., 2002, Koys and DeCotiis, 1991 and O'Reilly et al., 1991).

Past studies have suggested that innovativeness facilitates innovative behaviors in an organization. For example, Scott and Bruce (1994) conceptualized the 'psychological climate for innovation' as "the degree to which individuals viewed the organization as open to change, supportive of new ideas from workers, and tolerant of worker diversity" (p.592). Based on empirical studies, they reported that psychological climates for innovation have a positive impact on innovative behaviors. Amabile et al. (1996) also demonstrated that a work environment in which the organization or supervisor encourages creativity promotes individual creativity. Judging from this, innovativeness as one dimension of organizational climate or culture has been studied widely, in that it promotes individual innovative behaviors or creativity. Therefore, this study focuses on innovativeness as an organizational tendency that supports innovation in sales departments, and not as an innovation itself. Following Scott and Bruce (1994), departmental innovativeness is defined as a perceived work environment that encourages innovative behavior within a department.

\subsection{Conflict}

Earlier research examined conflict as an inhibitor of organizational productivity, and investigated the causes and solutions of conflict. Recent research, however, has insisted that conflict affects organizational members positively under some circumstances (Tjosvold, 1991). Conflict is defined as awareness on the part of the parties involved of discrepancies, incompatible wishes, or irreconcilable desires (Boulding, 1963). Previous research has shown that conflict is multidimensional, and can be classified into three types: relationship (or emotional), task (or cognitive), and process conflicts (Jehn, 1995, Amason, 1996, Pelled et al., 1999 and Jehn and Mannix, 2001).

Jehn and Mannix (2001) view these conflicts in the following way. Relationship conflict is "the awareness of interpersonal incompatibilities, including affective components such as the experience of tension and friction" (p.238). Task conflict refers to "the awareness of differences in viewpoints and opinions pertaining to a group task" (p.238); it is related to conflicts about ideas, and to differences in opinion about the task. Process conflict is "an awareness of controversy with respect to how tasks will be accomplished" (p.239). This conflict involves issues of duty and resource delegation. 
Previous empirical studies have reported that task conflict has a positive impact on group performance, while relationship and process conflict have a negative impact (Amason, 1996, Jehn, 1995, Jehn and Mannix, 2001 and Pelled et al., 1999). One problem is that few empirical studies have examined the relationship between conflict and innovation. This study therefore explores the impact of different kinds of conflict on innovativeness in sales departments.

\section{Hypothesized relationships}

The conceptual framework is presented in Fig. 1. In this research, the unit of analysis was the department, rather than the organization, since sub-cultures exist within an organization. Regarding this point, Desphande et al. (1989) suggested that it might be more productive to study culture at the departmental level because it relates to the development of a customer-oriented view of the business.

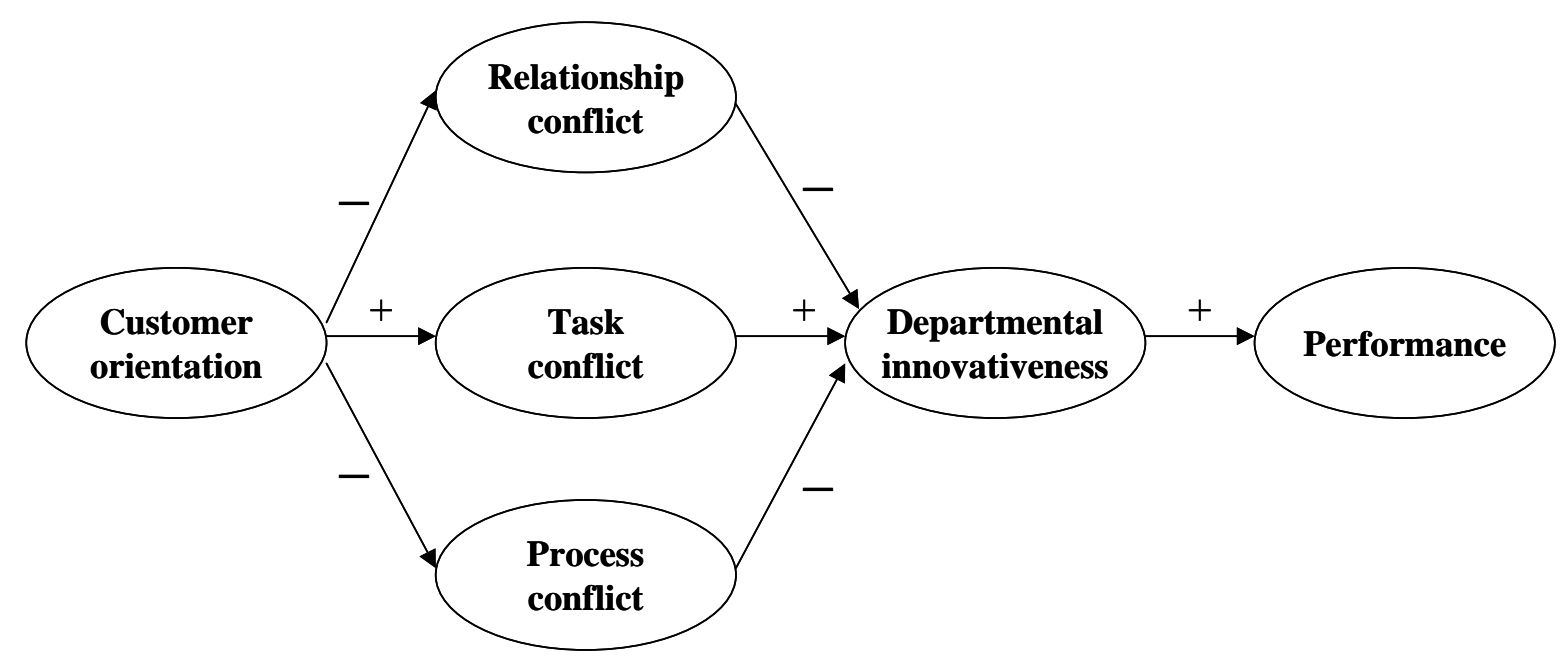

Fig. 1. Research model.

\subsection{Innovativeness and performance}

Empirical studies of organizational innovation have shown that there is a positive, direct relationship between innovation and business performance (Damanpour et al., 1989 and 
Han et al., 1998). The rationale behind the organizational innovativeness/performance relationship is that innovations function as a coping mechanism for environmental changes and uncertainties (Damanpour and Evan, 1984 and Han et al., 1998). As Drucker (1954) has noted, innovation constitutes a basic function, one that any business enterprise uses, in order to create customers. Some studies have indicated that innovativeness, as an organizational culture or climate, has a positive impact on a firm's performance. Hurley and Hult (1998) found that existing innovativeness of divisions in government agencies promoted the divisions' capacity to innovate, as well as the ability of the organization to adopt or implement new ideas, processes, or products successfully. Desphande et al. (1993) surveyed Japanese firms and reported that innovativeness was positively related to a firm's financial performance. These studies indicate that a firm's innovativeness enhances its performance because it encourages organization members to come up with innovative services and products in order to cope with technological and market changes. Therefore, the following hypothesis is proposed:

H1 Departmental innovativeness relates positively to financial performance.

\subsection{Conflict and innovativeness}

A variety of determinants that facilitate innovation and creativity within an organization have been studied thus far; these determinants include structure, slack resources, technology, and culture (Amabile et al., 1996, Damanpour, 1991, Frambach and Schillewaert, 2002, Glynn, 1996 and Woodman et al., 1993). Recently, some studies on organizational learning and innovation have stressed the role of creative conflict, including the functions of 'creative abrasion' (Leonard-Barton, 1995), 'creative chaos' (Nonaka and Takeuchi, 1995), 'productive conflict' (Jehn, 1995), and 'challenging tasks' (Amabile et al., 1996) in facilitating organizational innovation and learning.

Leonard-Barton (1995) has suggested that sparks produced when different ideas come together can be creative in a well-managed process. She comments that "creative abrasion is an antidote to core rigidities because it forces the constant re-examination of whatever perspective dominates at the time in the organization" (p.89). Nonaka and Takeuchi (1995) have argued that the leaders of top Japanese firms sometimes try to provoke a sense of crisis among members by proposing challenging goals, which, in turn, increases tension within the organization and focuses the attention of members on defining the problem and resolving the crisis. Amabile et al. (1996) have claimed that a degree of pressure can have a positive influence on innovation, if it is perceived as 
arising from the urgent, intellectually challenging nature of the problem itself. These studies suggest, generally, that creative conflict or other forms of pressure can promote innovation by encouraging members to reassess familiar practices, identify problems within an organization, and come up with creative solutions, if the conflict is linked to a challenging task. In this sense, creative abrasion and creative chaos are similar concepts to that of task conflict.

Although these studies have indicated the importance of creative conflict, few empirical studies have examined the concept. It is crucial to clarify what kind of conflict promotes innovation. To address this question, this study investigated the conflict/innovativeness relationship using intra-group conflict research that categorizes conflict into three types: task, process, and relationship conflict.

As noted above, conflict research suggests that task conflict benefits group performance (DeChurch and Marks, 2001 and Jehn and Mannix, 2001). Pelled et al. (1999) found that task conflict had a positive association with cognitive task performance in work groups. Amason (1996) reported that task conflict (cognitive conflict) is positively related to the quality of group decisions, the understanding of decisions, and affective acceptance of group members. The rationale behind its positive effect is that task conflict, or disagreements about the task, (a) makes members more receptive to new information, (b) fosters a deeper understanding of task issues, (c) increases the range of alternatives considered, (d) motivates assumption questioning, and (e) allows assumptions and recommendations to be evaluated systematically (Amason, 1996, Mason and Mitroff, 1981, Pelled et al., 1999, Schweiger et al., 1986 and Schwenk, 1990). Jehn et al. (1999) and Woodman et al. (1993) explained the task conflict/performance relationship with similar logic. Therefore:

H2 Task conflict relates positively to departmental innovativeness.

In contrast, some empirical studies have reported that relationship conflicts, or interpersonal incompatibilities or disputes, are detrimental to individual and group performance. Jehn (1995) found that relationship conflict is detrimental, regardless of the group task. Amason (1996) reported that affective conflict (relationship conflict) is negatively related to the quality of group decisions, commitment to the decisions, and to the acceptance of decisions on the part of group members. The rationale for the negative relationship is that relationship conflict makes members anxious and inhibits cognitive functioning; it also makes members less receptive to the ideas of other group members 
(Jehn, 1995, Jehn and Mannix, 2001 and Pelled, 1996). This discussion suggests the following hypothesis:

H3 Relationship conflict relates negatively to departmental innovativeness.

Although process conflict has been examined to a lesser extent than has task and relationship conflict (Jehn and Mannix, 2001), prior studies have suggested that process conflict, or controversy over how tasks will be accomplished, has a negative impact on group performance (Jehn, 1997 and Jehn et al., 1999). The rationale is that when a group argues about who does what, the conflict makes members dissatisfied with the uncertainty, and misdirects their focus to irrelevant discussions of members' ability (Jehn, 1997 and Jehn and Mannix, 2001). Therefore, the following hypothesis is proposed:

H4 Process conflict relates negatively to departmental innovativeness.

\subsection{Customer orientation and conflict}

Although intra-group conflict research has not shown how to generate constructive conflict (DeChurch and Marks, 2001), some studies have emphasized the role of shared objectives, identity, belief, and values in integrating diverse perspectives and ideas. Several studies point out that common objectives, values, or identity are necessary for generating task conflict and restraining relationship conflict (Amason, 1996, Jehn et al., 1999 and Mortensen and Hinds, 2001).

Some researchers in marketing and organizational research have contended that customer orientation can be a common value or goal integrating diverse perspectives within an organization. Dougherty (1992) argues that a realistic customer focus can overcome differences in the thought worlds that prevent innovators from synthesizing their expertise. Atuahene-Gima (1996) has claimed that market orientation provides the various components of a firm with common assumptions and beliefs about customer needs. Nonaka and Takeuchi (1995) have suggested that it is actually difficult to discuss a task constructively without a unifying focus or some redundancy. These studies suggest that customer orientation has a role in relation to dealing with conflict and integrating diverse opinions within an organization. If customer orientation provides a common standard for decisions within an organization, it may facilitate task conflict, and reduce relationship and process conflict by directing members' attention to their 
tasks rather than to the emotional relationships among members, or to resource allocation. This discussion leads to the following hypotheses:

H5 Customer orientation relates positively to task conflict.

H6 Customer orientation relates negatively to relationship conflict.

H7 Customer orientation relates negatively to process conflict.

\section{Research method}

\subsection{Sample}

The population examined in this study consisted of the sales departments of large and medium-sized Japanese companies. Large and medium-sized companies were chosen because many small companies lack a differentiated, autonomous sales department.

A sample of 1000 companies with headquarters in Tokyo or Osaka was drawn from companies in the first section of the Tokyo Stock Exchange. A questionnaire entitled "Sales Management Survey", with a cover letter explaining the purpose of the survey, was mailed to the sales directors of these companies. As it was difficult to identify the sales manager of each firm's main product or service, the cover letter asked the sales director to hand over the questionnaire to the manager of the sales department dealing with the firm's main product or service.

Four weeks later, a postcard reminder was sent to firms that had not responded. Of the 1000 questionnaires mailed, 213 were returned. A summary of the research findings was offered as an incentive to the respondents. In order to ensure the validity of the answers, the answers from non-managers were deleted because they may not be knowledgeable about the department. As a result, 193 questionnaires were considered usable after removing missing answers (response rate: 19.3\%). The sample consisted of $72.1 \%$ manufacturers and $27.9 \%$ non-manufacturers. Regarding the number of employees, $34.6 \%$ of the sample companies employed 999 people or less, $47.3 \%$ had between 1000 and 4999 employees, and 17.5\% had more than 5000 employees. 


\subsection{Measures}

Multiple-item scales were developed based on items previously proposed in survey research studies (Jehn and Mannix, 2001, Narver and Slater, 1990 and Scott and Bruce, 1994). The scale items were translated from English to Japanese, and checked by a bilingual marketing researcher who did not know the purpose of this study. The means, standard deviations, and correlations among the variables are shown in Table 1.

Table 1. Correlation among variables

\begin{tabular}{|l|l|l|l|l|l|l|l|l|}
\hline & Variable & Mean & S.D. & $\mathbf{1}$ & $\mathbf{2}$ & $\mathbf{3}$ & $\mathbf{4}$ & $\mathbf{5}$ \\
\hline 1 & Customer orientation & 4.86 & 1.15 & & & & & \\
\hline 2 & Task conflict & 4.84 & .95 & $.21^{*}$ & & & & \\
\hline 3 & Relationship conflict & 3.80 & 1.07 & .01 & $.33^{*}$ & & & \\
\hline 4 & Process conflict departmental & 3.46 & 1.24 & -.14 & $.19^{*}$ & $.35^{*}$ & & \\
\hline 5 & Innovativeness & 4.65 & 1.00 & $.25^{*}$ & $.31^{*}$ & -.11 & $-.33^{*}$ & \\
\hline 6 & Performance & 4.34 & 1.22 & $.29^{*}$ & .11 & -.01 & -.10 & $.22^{*}$ \\
\hline
\end{tabular}

$N=193$.

${ }^{*} p<.01$.

\subsubsection{Conflict}

Three types of intra-organizational conflict were measured using the scales developed by Jehn and Mannix (2001). The structural equation model results (Table 2) indicate that the factor structure corresponded to that of the original scale examined by Jehn and Mannix (2001).

The moderate correlations between task, relationship, and process conflict, ranging from .19 to .35 , implied that the three types of conflict, which are discriminated theoretically, are not highly correlated in reality. Each item measured conflict on a seven-point Likert scale $(1=$ not at all, 7 = a lot). Cronbach's alpha for task, relationship, 
and process conflict was $.77, .72$, and .84 , respectively. The scores for each item were used as observable variables.

\subsubsection{Customer orientation}

This study adopted the customer orientation scale developed by Narver and Slater (1990). The scale consists of six items (customer commitment, create customer value, understand customer needs, customer satisfaction objectives, measure customer satisfaction, after-sales service). Each item measured customer orientation on a seven-point Likert scale ( $1=$ strongly disagree, $7=$ strongly agree $)$. The six items were subjected to a principal component analysis with oblique rotation, and one factor solution resulted. This means that customer orientation is a single factor structure, which is consistent with the original scale of Narver and Slater (1990). Cronbach's alpha was .89. The scores for each item were used as observable variables.

\subsubsection{Departmental innovativeness}

To measure the departmental innovativeness, the scale of the climate for innovation developed by Scott and Bruce (1994) was used. The original measure contained two subscales: (1) support for innovation, and (2) resource supply. Since the resource supply subscale deals with the degree of slack resource rather than the tendency to encourage innovative behavior it was not used in this study. The 16 items were subjected to a principal component analysis with oblique rotation. Because it was difficult to identify the theoretical dimensions of this scale in advance, exploratory factor analysis (EFA) was used resulting in a three-factor solution. Factor 1 (6 items) was named tolerance of diversity; it measures the degree to which members are expected to think and deal with

problems in different ways. Factor 2 (6 items) was named encouragement of innovation; it measures the degree to which members are encouraged to be creative and open to change. Factor 3 (4 items) was named breaking the status quo; it measures the degree to which members do not stick to previous ways of working. Among the three factors, encouragement of innovation was adopted for departmental innovativeness scale because the factor resembles the original dimension of support for innovation developed

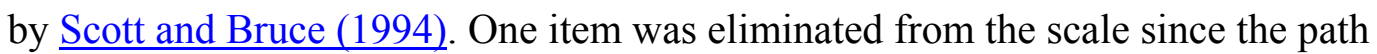
estimate was extremely low $(\lambda=.16)$. Each item measured departmental innovativeness on a seven-point Likert scale $(1=$ strongly disagree, $7=$ strongly agree $)$. Cronbach's alpha was .83. The five items were reverse-coded, and used as observable variables. 


\subsubsection{Performance}

Performance was measured with two items: 'overall performance of the department' and 'profitability (e.g., return on investment) of the department relative to competitors in the last three years. Each item measured performance on seven-point scales $(1=$ very low, $7=$ very high). Cronbach's alpha was .84 . The scores for each item were used as observable variables.

This study adopted subjective measures of performance, yet some researchers report that objective measures are highly related to subjective measures. For example, Barling et al. (1996) measured car salespeople's performance using annual vehicle sales and evaluations by general managers, and reported that both measures were significantly related. Jaworski and Kohli (1991) reported a high correlation between output performance and behavioral performance $(r=.57)$. Therefore, using subjective measures alone may not bias the results significantly.

\section{Results}

Descriptive statistics and inter-correlations among variables are presented in Table 1. Structural equation modeling (SEM) was conducted to test the proposed research model because SEM allows us to examine multiple relationship simultaneously while also incorporating measurement error into the estimation process. Fig. 1 presents the estimated model. Estimation of the hypothesized model resulted in $\chi^{2}=369.34$ $(d f=203, p<.001), \mathrm{RMSEA}=.07, \mathrm{GFI}=.85, \mathrm{CFI}=.90$. A possible explanation for the chi-squared value is this statistic's sensitivity to sample size. Other indices showed relatively adequate fits.

The standardized path coefficients for the model are presented in Table 2. Departmental innovativeness is positively related to performance $(\beta=.28, p<.01)$. This supports $\underline{\mathrm{H} 1}$. Task conflict was positively related to departmental innovativeness $(\beta=.51, p<.001)$, indicating that a sales department with task conflict tends to be innovative. Therefore, $\underline{\mathrm{H} 2}$ was supported. Relationship conflict was negatively related to departmental innovativeness $(\beta=-.16, p<.05)$, which supports $\underline{\mathrm{H} 3}$. Process conflict was negatively related to departmental innovativeness $(\beta=-.41, p<.001)$, as predicted in $\underline{\mathrm{H} 4}$. The results indicate that process conflict and relationship conflict are destructive to innovativeness. 
As hypothesized (H5 and H6), customer orientation was positively related to task conflict and negatively related to process conflict $(\beta=26, p<.01 ; \beta=-.16, p<.05$, respectively). However, the effect of customer orientation on relationship conflict was not significant $(\beta=-.01$, n.s.). Therefore, $\underline{\mathrm{H} 6}$ was not supported. These results suggest that customer orientation promotes task conflict, restrains process conflict, and has no effect on relationship conflict.

Table 2. Structural model estimates $(N=193)$

\begin{tabular}{|c|c|c|}
\hline & Estimate $^{\mathbf{a}}$ & $t$-value \\
\hline \multicolumn{3}{|l|}{ Structural paths } \\
\hline Customer orientation $\rightarrow$ Relationship conflict & -.01 & -.03 \\
\hline Customer orientation $\rightarrow$ Task conflict & .26 & 2.92 \\
\hline Customer orientation $\rightarrow$ Process conflict & -.16 & -1.91 \\
\hline Process conflict $\rightarrow$ Department innovativeness & -.41 & -5.16 \\
\hline Task conflict $\rightarrow$ Department innovativeness & .51 & 5.51 \\
\hline Relationship conflict $\rightarrow$ Department innovativeness & -.16 & -1.98 \\
\hline Department innovativeness $\rightarrow$ Performance & .28 & 2.98 \\
\hline \multicolumn{3}{|l|}{ Measurement model } \\
\hline \multicolumn{3}{|l|}{ Task conflict $(\alpha=.77)^{\mathrm{b}}$} \\
\hline Conflict of ideas ${ }^{\mathrm{c}}$ & .67 & - \\
\hline Conflicting opinions about the task & .74 & 8.14 \\
\hline Disagreements about the task & .77 & 8.33 \\
\hline \multicolumn{3}{|l|}{ Process conflict $(\alpha=.84)^{\underline{b}}$} \\
\hline Disagreements about who should do what ${ }^{\underline{\underline{c}}}$ & .86 & - \\
\hline
\end{tabular}




\begin{tabular}{|c|c|c|}
\hline & Estimate $^{\mathrm{a}}$ & $t$-value \\
\hline Conflict about task responsibility & .78 & 10.86 \\
\hline Disagreements about resource allocation & .76 & 10.61 \\
\hline \multicolumn{3}{|l|}{ Relationship conflict $(\alpha=.72)^{\underline{b}}$} \\
\hline Emotional conflict ${ }^{\mathrm{c}}$ & .76 & - \\
\hline Relationship tension & .55 & 5.85 \\
\hline People get angry while working & .73 & 6.12 \\
\hline \multicolumn{3}{|l|}{ Customer orientation $(\alpha=.89)^{\underline{b}}$} \\
\hline After-sales service ${ }^{\mathrm{c}}$ & .58 & - \\
\hline Monitor customer commitment & .80 & 8.21 \\
\hline Customer satisfaction objectives & .82 & 8.33 \\
\hline Understand customer needs & .81 & 8.31 \\
\hline Create customer value & .80 & 8.25 \\
\hline Measure customer satisfaction & .74 & 7.86 \\
\hline \multicolumn{3}{|l|}{ Departmental innovativeness $(\alpha=.83)^{\mathrm{b}}$} \\
\hline The main function of members is to follow orders ${ }^{\mathrm{c} \text { and } \mathrm{d}}$ & .74 & - \\
\hline A person can get in a lot of trouble by being different ${ }^{\frac{d}{~}}$ & .73 & 9.04 \\
\hline People are expected to deal with problems in the same way ${ }^{\mathrm{d}}$ & .60 & 7.50 \\
\hline A person can't do things that are too different ${ }^{\mathrm{d}}$ & .66 & 8.21 \\
\hline The people in charge usually get credit for others' ideas ${ }^{\underline{d}}$ & .62 & 7.78 \\
\hline \multicolumn{3}{|l|}{ Performance $(\alpha=.84)^{\underline{b}}$} \\
\hline Profitability of the department $\stackrel{\mathrm{c}}{\mathrm{c}}$ & .83 & - \\
\hline Overall performance of the department & .87 & 4.10 \\
\hline
\end{tabular}


${ }^{a}$ Value represents standardized estimate.

b ' $\alpha$ ' represent Cronbach's alpha.

${ }^{\mathrm{c}}$ The corresponding parameter is fixed to a value of 1.00 to set the scale of measurement.

${ }^{\mathrm{d}}$ Item was reverse-coded.

\section{Discussion}

\subsection{Theoretical implication}

The main purpose of this study was to investigate how customer orientation affects innovativeness through conflicts in the sales departments of Japanese firms. Despite the argument over the customer orientation/innovation linkage (Christensen and Bower, 1996, Leonard-Barton, 1995 and Slater and Narver, 1994), only a few studies have examined the relationship between customer orientation and innovation empirically (Lukas and Ferrell, 2000).

This study found that (1) customer orientation was positively related to task conflict, but negatively related to process conflict, (2) task conflict was positively related to departmental innovativeness, while process and relationship conflict was negatively related to departmental innovativeness, and (3) departmental innovativeness was positively related to the financial performance of sales departments. The results indicate that customer orientation enhances innovativeness by promoting task conflict and restraining process conflict.

The theoretical contribution of this study to the marketing literature can be summarized as follows. First, it clarified the role of conflict in linking customer orientation to innovativeness. This relationship has been identified by a number of researchers (Dougherty, 1992 and Nonaka and Takeuchi, 1995), but not examined empirically. Although this study did not investigate how customer orientation promotes creative conflict, one explanation of this finding is that customer orientation provides a common goal or unifying focus for the efforts and projects of individuals within a department (Kohli and Jaworski, 1990, Dougherty, 1992 and Atuahene-Gima, 1996). Perhaps customer orientation, as a common goal, integrates diverse opinions and reduces destructive conflict within an organization. Customer orientation might direct salespeople's attention to the task itself, rather than to resource allocation, and might help to make conflicts constructive and creative. 
As Nonaka and Takeuchi (1995) have pointed out, a unifying focus is indispensable for synthesizing the diverse perspectives needed to generate innovation. Mortensen and Hinds (2001) reported that shared team identity reduced the negative effect of conflict within a team. Jehn et al. (1999) also found that value diversity decreased satisfaction, intent to remain, and commitment to the group, as mediated through relationship conflict. Since customer orientation is defined as the pattern of shared values and beliefs that puts the customer's interest first (Desphande et al., 1993 and Gatignon and Xuereb, 1997), it is possible to interpret the results as showing that customer orientation can synthesize and integrate diverse ideas and perspectives within a specific organization by generating constructive conflict. Future studies should examine this interpretation.

Second, the results indicated that task conflict facilitates departmental innovativeness, while process and relationship conflict restricts it. As few studies have examined the conflict/innovativeness relationship, the findings may provide insight that will help us to understand the process of creative conflict. Some authors have suggested that forms of constructive conflict, such as creative abrasion (Leonard-Barton, 1995) and creative chaos (Nonaka and Takeuchi, 1995), are necessary for promoting innovation. The results suggest that innovative conflict involves more task conflict and less process and relationship conflict. One possible explanation for the conflict/innovativeness relationship unfolds as follows. Task conflict might enhance a sales department's innovativeness by making salespeople more receptive to new information, by increasing the range of alternatives considered, and by motivating assumption questioning (Mason and Mitroff, 1981, Schweiger et al., 1986, Schwenk, 1990 and Amason, 1996). In contrast, process and relationship conflict might hinder the innovativeness of a sales department by misdirecting salespeople to focus on non-task-related discussions (Amason, 1996, Jehn, 1995, Jehn, 1997, Jehn and Mannix, 2001 and Pelled et al., 1999). These explanations should be tested empirically in the future.

Finally, the results explain customer orientation/performance in terms of intra-organizational conflict and innovativeness. This suggests that customer orientation not only helps a firm to adapt to the external environment, but that it also helps to integrate internal resources. However, there must be other factors that contribute to explaining the customer orientation/performance relationship. These factors should be investigated in the future. 


\subsection{Managerial implications}

This study has two managerial implications, especially for sales departments. First, sales managers should note that the customer orientation/performance relationship is not simple. For sales managers to enhance the performance of their departments, they need to focus on the role of customer orientation in generating constructive conflicts that promote departmental innovativeness. By strengthening customer focus, managers can encourage members to come up with diverse viewpoints and ideas, and minimize negative conflicts among members. Sales managers should note that customer orientation, as a shared goal, identity, or value, could integrate diverse perspectives within an organization.

Second, sales managers should distinguish task conflict from process conflict. Task conflict refers to disagreement over opinions and ideas about the task, which has a positive effect on innovativeness. By contrast, process conflict means disagreement about resource and job allocation, and this disturbs innovativeness. Since both types of conflict are related to the task, it is sometimes difficult to distinguish them. Sales managers must monitor the characteristics of conflicts within their departments, and encourage members to discuss the nature and content of tasks, but to avoid disputes over resource allocation. It may be crucial for managers to get department members to focus on the task itself.

\subsection{Limitations and future research}

The limitations of this study should be acknowledged. First, as the study was cross-sectional in design, it is difficult to draw causal inferences from the results. Therefore, we can only claim associations between variables.

Second, this study did not test the mechanisms by which customer orientation affects forms of conflict, and how conflicts influence innovativeness. The results were simply interpreted based on previous studies (Amason, 1996, Atuahene-Gima, 1996, Dougherty, 1992, Mason and Mitroff, 1981, Schweiger et al., 1986, Schwenk, 1990 and Pelled et al., 1999). The hypothesized mechanisms should be examined in future research.

Third, the single respondent sampling design is a concern. To minimize this concern, sales managers, who are assumed to be knowledgeable about the situation in a sales department, were asked to answer the questionnaire. In addition, the answers from 
non-managers were deleted from the data. However, further research should test causal relationships using longitudinal data from multiple informants.

Fourth, it is necessary to consider the moderating effect of task type on the customer orientation/performance relationship. Jehn (1995) suggested that task conflict has a detrimental effect on group functioning in groups performing routine tasks. The positive relationship between task conflict and innovativeness seen in this study indicates that tasks in the sales departments in Japanese firms tend to be non-routine. However, it is necessary to examine the moderating effect of task trait on the model presented here in future research.

Finally, the data were limited to the sales departments in Japanese firms. The study needs to be extended to an international context and to other functional departments in order to generalize the findings. Since conflicts often arise among different functional departments, additional research is needed to test the model.

Despite these limitations, the empirical evidence reported here will stimulate studies on conflict and innovation. This study suggested that customer orientation plays a key role in generating constructive conflicts by promoting task conflict and reducing process conflict, which enhance innovativeness. Continued research into the mechanism should advance our understanding of conflict and innovation processes within organizations.

\section{References}

Amabile et al., 1996 T.M. Amabile, R. Conti, R.H. Coon, J. Lazenby and M. Herron, Assessing the work environment for creativity, Acad Manage J 39 (1996) (5), pp. 1154-1184.

Amason, 1996 A.C. Amason, Distinguishing the effects of functional and dysfunctional conflict on strategic decision making: resolving a paradox for top management teams, Acad Manage J 39 (1996) (1), pp. 123-148. 
Anderson and Narus, 1995 J.C. Anderson and J.A. Narus, Capturing the value of supplementary services, Harvard Bus Rev (1995), pp. 75-83.

Atuahene-Gima, 1996 K. Atuahene-Gima, Market orientation and innovation, J Bus Res 35 (1996), pp. 93-103.

Barling et al., 1996 J. Barling, E.K. Kelloway and D. Cheung, Time management and achievement striving interact to predict car sales performance, J Appl Psychol 81 (1996) (6), pp. 821-826.

Boulding, 1963 K. Boulding, Conflict and defense, Harper and Row, New York (1963).

Brown and Duguid, 1991 J.S. Brown and P. Duguid, Organizational learning and communities-of-practice: toward a unified view of working, learning, and innovation, Organ Sci 2 (1991) (1), pp. 40-57.

Chatman and Jhen, 1994 J.A. Chatman and K.A. Jhen, Assessing the relationship between industry characteristics and organizational culture: how different can you be?, Acad Manage J 37 (1994), pp. 522-553.

Christensen and Bower, 1996 C.M. Christensen and J.L. Bower, Customer power, strategic investment, and the failure of leading firms, Strateg Manage J 17 (1996), pp. $197-218$.

Damanpour, 1991 F. Damanpour, Organizational innovation: a meta-analysis of effects of determinants and moderators, Acad Manage J 34 (1991) (3), pp. 555-590.

Damanpour and Evan, 1984 F. Damanpour and W.M. Evan, Organizational innovation and performance: the problem of “organizational lag”, Adm Sci Q 29 (1984), pp. $392-409$.

Damanpour and Gopalakrishnan, 2001 F. Damanpour and S. Gopalakrishnan, The dynamics of the adoption of product and process innovations in organizations, J Manag Stud 38 (2001) (1), pp. 45-65.

Damanpour et al., 1989 F. Damanpour, K.A. Szabat and W.M. Evan, The relationship between types of innovation and organizational performance, J Manag Stud 26 (1989) (6), pp. 587-601. 
DeChurch and Marks, 2001 L.A. DeChurch and M.A. Marks, Maximizing the benefits of task conflict: the role of conflict management, Int J Confl Manage 12 (2001) (1), pp. $4-22$.

Desphande et al., 1989 R. Desphande, J.U. Farley and F.E. Webster, Organizational culture and marketing: defining the research agenda, J Mark 53 (1989), pp. 3-15 [January].

Desphande et al., 1993 R. Desphande, J.U. Farley and F.E. Webster, Corporate culture, customer orientation, and innovativeness in Japanese firms: a quadrad analysis, $J$ Mark 57 (1993), pp. 23-37.

Donavan et al., 2004 D.T. Donavan, T.J. Brown and J.C. Mowen, Internal benefits of service-worker customer orientation: job satisfaction, commitment, and organizational citizenship behaviors, J Mark 68 (2004), pp. 128-146.

Dougherty, 1992 D. Dougherty, Interpretive barriers to successful product innovation in large firms, Organ Sci 3 (1992) (2), pp. 179-202.

Drucker, 1954 P.F. Drucker, The practice of management, Harper and Row Publishers, Inc., New York (1954).

Dubinsky et al., 1996 A.J. Dubinsky, R.D. Howell, T.N. Ingram and D.N. Bellenger, Salesforce socialization, J Mark 50 (1996), pp. 192-207.

Eisenhardt and Santos, 2002 K.M. Eisenhardt and F.M. Santos, Knowledge-based view: a new theory of strategy?. In: A. Pettigrew, T.H. Thomas and R. Whittington, Editors, Handbook of strategy and management, Sage, London (2002).

Frambach and Schillewaert, 2002 R.T. Frambach and N. Schillewaert, Organizational innovation adoption: a multi-level framework of determinants and opportunities for future research, J Bus Res 55 (2002), pp. 163-176.

Gatignon and Xuereb, 1997 H. Gatignon and J. Xuereb, Strategic orientation of the firm and new product performance, J Mark Res 34 (1997), pp. 77-90. 
Glynn, 1996 M.A. Glynn, Innovative genius: a framework for relating individual and organizational intelligences to innovation, Acad Manage Rev 21 (1996) (4), pp. 1081-1111.

Ghosn, 2001a C. Ghosn, The key for successful alliance is consensus-oriented management, Hitotsubashi Bus Rev (2001), pp. 164-179 [Winter] [in Japanese].

Ghosn, 2001b C. Ghosn, Renaissance, Diamond, Tokyo (2001).

Hamel and Prahalad, 1994 G. Hamel and C.K. Prahalad, Competing for the future, Harvard Business School Press, Boston (1994).

Han et al., 1998 J.K. Han, N. Kim and R.K. Srivastava, Market orientation and organizational performance: is innovation a missing link?, J Mark 62 (1998), pp. 30-45.

Hult et al., 2002 G.T.M. Hult, D.J. Ketchen and E.L. Nichols, An examination of cultural competitiveness and order fulfillment cycle time within supply chains, Acad Manage J 45 (2002) (3), pp. 577-586.

Hurley and Hult, 1998 R.F. Hurley and T.M. Hult, Innovation, market orientation, and organizational learning: an integration and empirical examination, J Mark 62 (1998), pp. 42-54.

Jaworski and Kohli, 1991 B.J. Jaworski and A.K. Kohli, Supervisory feedback: alternative types and their impact on salespeople's performance and satisfaction, $J$ Mark Res 28 (1991), pp. 190-201 [May].

Jehn, 1995 K.A. Jehn, A multimethod examination of the benefits and detriments of intragroup conflict, Adm Sci $Q 40$ (1995), pp. 256-282.

Jehn, 1997 K.A. Jehn, A qualitative analysis of conflict types and dimensions in organizational groups, Adm Sci $Q 42$ (1997) (3), pp. 530-557.

Jehn and Mannix, 2001 K.A. Jehn and E.A. Mannix, The dynamic nature of conflict: a longitudinal study of intragroup conflict and group performance, Acad Manage J 44 (2001) (2), pp. 238-251. 
$\underline{\text { Jehn et al., } 1999}$ K.A. Jehn, G.B. Northcraft and M.A. Neale, Why differences make a difference: a field study of diversity, conflict, and performance in workgroups, Adm Sci Q 44 (1999), pp. 741-763.

Kennedy et al., 2003 K.N. Kennedy, J.R. Goolsby and E.J. Arnould, Implementing a customer orientation: extension of theory and application, J Mark 67 (2003), pp. 67-81.

Kohli and Jaworski, 1990 A.K. Kohli and B.J. Jaworski, Market orientation: the construct, research propositions, and managerial implications, J Mark 54 (1990), pp. $1-18$.

Koys and DeCotiis, 1991 D.J. Koys and T.A. DeCotiis, Inductive measures of psychological climate, Hum Relat 44 (1991) (3), pp. 265-285.

Lawton and Parasuraman, 1980 L. Lawton and A. Parasuraman, The impact of the marketing concept on new product planning, J Mark 44 (1980), pp. 19-25.

Leonard-Barton, 1995 D. Leonard-Barton, Wellsprings of knowledge: building and sustaining the sources of innovation, Harvard Business School Press, Boston (1995).

Leonard-Barton and Straus, 1997 D. Leonard-Barton and S. Straus, Putting your company's whole brain to work, Harvard Bus Rev (1997), pp. 111-121 [July-August].

Lukas and Ferrell, 2000 B.A. Lukas and O.C. Ferrell, The effect of market orientation on product innovation, J Acad Mark Sci 28 (2000) (2), pp. 239-247.

Mason and Mitroff, 1981 R.O. Mason and I.I. Mitroff, Challenging strategic planning assumptions, Wiley, New York (1981).

Mortensen and Hinds, 2001 M. Mortensen and P.J. Hinds, Conflict and shared identity in geographically distributed teams, Int J Confl Manage 12 (2001) (3), pp. 212-238.

Narver and Slater, 1990 J.C. Narver and S.F. Slater, The effect of a market orientation on business profitability, J Mark 54 (1990), pp. 20-35.

Nonaka and Takeuchi, 1995 I. Nonaka and H. Takeuchi, The knowledge creating company, Oxford University Press, New York (1995). 
O'Reilly et al., 1991 C. O'Reilly, J. Chatman and D.F. Caldwell, People and organizational culture: a profile comparison approach to assessing person-organization fit, Acad Manage J 34 (1991), pp. 487-516.

Pelled, 1996 L.H. Pelled, Demographic diversity, conflict, and work group outcomes: an intervening process theory, Organ Sci 6 (1996), pp. 615-631.

Pelled et al., 1999 L.H. Pelled, K.M. Eisenhardt and K.R. Xin, Exploring the black box: an analysis of work group diversity, conflict, and performance, Adm Sci Q 44 (1999), pp. $1-28$.

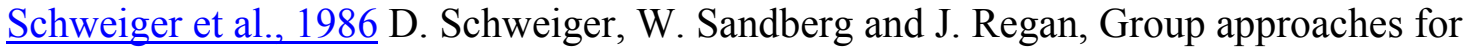
improving strategic decision making: a comparative analysis of dialectical inquiry, devil's advocacy, and consensus approaches to strategic decision making, Acad Manage $J 29$ (1986), pp. 51-71.

Schwenk, 1990 C. Schwenk, Conflict in organizational decision making: an exploratory study of its effects in for-profit and non-for-profit organizations, Manage Sci 36 (1990), pp. 436-448.

Scott and Bruce, 1994 S.G. Scott and R.A. Bruce, Determinants of innovative behavior: a path model of individual innovation in the workplace, Acad Manage J 37 (1994) (3), pp. 580-607.

Shepherd, 1999 C.D. Shepherd, Service quality and the sales force: a tool for competitive advantage, J Pers Sell Sales Manage 19 (1999) (3), pp. 73-82.

Singh, 1998 J. Singh, Striking a balance in boundary-spanning positions: an investigating of some unconventional influences of role stressors and job characteristics on job outcomes of salespeople, J Mark 62 (1998), pp. 69-86.

Slater and Narver, 1994 S.F. Slater and J.C. Narver, Does competitive environment moderate the market orientation-performance relationship?, J Mark 58 (1994), pp. $46-55$.

Tjosvold, 1991 D. Tjosvold, Rights and responsibilities of dissent: cooperative conflict, Employ Responsib Rights J 4 (1991), pp. 13-23. 
Ulwick, 2002 A.W. Ulwick, Turn customer input into innovation, Harvard Bus Rev (2002), pp. 91-97.

Weitz and Bradford, 1999 B.A. Weitz and K.D. Bradford, Personal selling and sales management: a relationship marketing perspective, J Acad Mark Sci 27 (1999) (2), pp. 241-254.

Woodman et al., 1993 R.W. Woodman, J.E. Sawyer and R.W. Griffin, Toward a theory of organizational creativity, Acad Manage Rev 18 (1993) (2), pp. 293-321. 